\title{
Preparation of $\mathrm{Al}_{2} \mathrm{O}_{3}$ and $\mathrm{AIN}$ Nanotubes by Atomic Layer Deposition
}

\author{
Cagla Ozgit ${ }^{1}$, Fatma Kayaci ${ }^{1}$, Inci Donmez ${ }^{1}$, Engin Cagatay $^{1}$, Tamer Uyar ${ }^{1}$, and Necmi Biyikli ${ }^{1}$ \\ ${ }^{1}$ UNAM - Institute of Materials Science and Nanotechnology, Bilkent University, Ankara \\ 06800, Turkey.
}

\begin{abstract}
$\mathrm{Al}_{2} \mathrm{O}_{3}$ and $\mathrm{AlN}$ nanotubes were fabricated by depositing conformal thin films via atomic layer deposition (ALD) on electrospun nylon 66 (PA66) nanofiber templates. Depositions were carried out at $200^{\circ} \mathrm{C}$, using trimethylaluminum (TMAl), water $\left(\mathrm{H}_{2} \mathrm{O}\right)$, and ammonia $\left(\mathrm{NH}_{3}\right)$ as the aluminum, oxygen, and nitrogen precursors, respectively. Deposition rates of $\mathrm{Al}_{2} \mathrm{O}_{3}$ and $\mathrm{AlN}$ at this temperature were $\sim 1.05$ and $0.86 \AA$ /cycle. After the depositions, $\mathrm{Al}_{2} \mathrm{O}_{3^{-}}$- and $\mathrm{AlN}$-coated nanofibers were calcinated at $500^{\circ} \mathrm{C}$ for $2 \mathrm{~h}$ in order to remove organic components. Nanotubes were characterized by using X-ray photoelectron spectroscopy (XPS), scanning electron microscopy (SEM), and transmission electron microscopy (TEM). AlN nanotubes were polycrystalline as determined by high resolution TEM (HR-TEM) and selected area electron diffraction (SAED). TEM images of all the samples reported in this study indicated uniform wall thicknesses.
\end{abstract}

\section{INTRODUCTION}

Atomic layer deposition (ALD) is a special type of low-temperature chemical vapor deposition, in which the substrate is exposed to sequential pulses of two or more precursors separated by purging periods [1]. Unless decomposition of the precursor occurs, each pulse leads to surface reactions that terminate after the adsorption of a single monolayer. Film growth mechanism of ALD is therefore self-limiting, which gives rise to unique properties such as high uniformity and conformality, as well as sub-nanometer thickness control.

In 2007, Peng et al. [2] combined ALD with electrospinning in order to fabricate long and uniform metal-oxide microtubes with precise wall thickness control. In their study, $\mathrm{Al}_{2} \mathrm{O}_{3}$ was deposited on electrospun poly(vinyl alcohol) microfibers, which were then removed by calcination. This approach was followed by other researchers, who synthesized tubes of various sizes, materials $\left(\mathrm{Al}_{2} \mathrm{O}_{3}[3,4], \mathrm{TiO}_{2}[5,6], \mathrm{ZnO}[3,4,7-9]\right)$, and structures (e.g. core-shell nanofibers) using different electrospun templates (nylon-6 [4], poly(vinyl acetate) [7-9], poly(vinyl alcohol) [3], poly(vinyl pyrrolidone) [5,6]).

Here we report on the fabrication of $\mathrm{Al}_{2} \mathrm{O}_{3}$ and $\mathrm{AlN}$ nanotubes by depositing conformal thin films via ALD on electrospun nylon 66 nanofiber templates. Chemical composition and bonding states of the nanotubes were investigated by XPS, whereas structural characterization was carried out by electron microscopy and diffraction. 


\section{EXPERIMENTAL DETAILS}

Nylon 66 (PA66) nanofiber templates were prepared by electrospinning of formic acid and hexafluoroisopropanol (HFIP) solutions. Different polymer concentrations were used according to solvent systems in order to obtain nanofibers having different diameters (see table I). For all the polymer solutions studied; feed rate, applied voltage and tip-to-collector distance were 1 $\mathrm{ml} / \mathrm{h}, 15 \mathrm{kV}$ and $10 \mathrm{~cm}$, respectively. Morphology, uniformity, and dimensions of electrospun nanofibers were studied by using scanning electron microscopy (SEM).

$\mathrm{Al}_{2} \mathrm{O}_{3}$ and $\mathrm{AlN}$ depositions were carried out at $200^{\circ} \mathrm{C}$ in Savannah S100 and Fiji F200-LL ALD reactors (Cambridge Nanotech), respectively. Deposition rates of $\mathrm{Al}_{2} \mathrm{O}_{3}$ and $\mathrm{AlN}$ at this temperature were $\sim 1.05$ and $0.86 \AA$ /cycle. 300 cycles of $\mathrm{Al}_{2} \mathrm{O}_{3}$ were deposited using trimethylaluminum (TMAl) and $\mathrm{H}_{2} \mathrm{O}$ as the aluminum and oxygen precursors, respectively. $\mathrm{N}_{2}$ was used as the carrier gas with a flow rate of $20 \mathrm{sccm}$. After the deposition, alumina-coated nanofibers were calcinated at $500^{\circ} \mathrm{C}$ for $2 \mathrm{~h}$ under atmospheric conditions in order to remove the organic component. 300 and 800 cycles of AlN were deposited via plasma-enhanced ALD (PEALD) using TMAl and ammonia $\left(\mathrm{NH}_{3}\right) . \mathrm{NH}_{3}$ flow rate and plasma power were $50 \mathrm{sccm}$ and $300 \mathrm{~W}$, respectively. Ar was used as the carrier gas with a flow rate of $60 \mathrm{sccm}$. In-situ calcination of the AlN-coated nanofibers was performed at $500^{\circ} \mathrm{C}$ for $2 \mathrm{~h}$.

Chemical composition and bonding states of the AlN nanotubes were determined by X-ray photoelectron spectroscopy (XPS) using Thermo Scientific K-Alpha spectrometer with a monochromatized Al Ka X-ray source. Electron microscopy studies were carried out by using FEI Quanta 200 FEG scanning electron and FEI Tecnai G2 F30 transmission electron microscopes.

Table I. Properties of PA66 solutions and the resulting electrospun nanofibers.

\begin{tabular}{|lllll|}
\hline $\begin{array}{l}\text { Solvent } \\
\text { system }\end{array}$ & \begin{tabular}{l} 
\% PA66 \\
\cline { 2 - 4 }
\end{tabular} & Viscosity & $\begin{array}{l}\text { Fiber } \\
\text { diameter }\end{array}$ & $\begin{array}{l}\text { Fiber } \\
\text { morphology }\end{array}$ \\
\hline Formic acid & 8 & (PA.s) & (nm) & Bead-free \\
\hline HFIP & 5 & 0.0493 & $67 \pm 35$ & Bead-free \\
\hline HFIP & 8 & 0.0413 & $330 \pm 83$ & Bead-free \\
\hline
\end{tabular}

\section{DISCUSSION}

SEM images of electrospun PA66 nanofiber templates are given in figure 1. Electrospinning of $8 \%$ formic acid solution resulted with an average fiber diameter of $\sim 70 \mathrm{~nm}$, whereas 5 and $8 \%$ hexafluoroisopropanol (HFIP) solutions produced fibers having average fiber diameters of $\sim 330$ and $\sim 740 \mathrm{~nm}$.

By controlling the electrospinning and ALD process parameters, $\mathrm{Al}_{2} \mathrm{O}_{3}$ and $\mathrm{AlN}$ nanotubes having different diameters and wall thicknesses were fabricated. SEM image of $\sim 740 \mathrm{~nm}$ diameter PA66 nanofiber template after deposition of 300 cycles $\mathrm{Al}_{2} \mathrm{O}_{3}$ is given in figure 2(a). As seen from this image, the self-limiting growth mechanism of ALD resulted with a highly 
uniform and conformal alumina layer on electrospun PA66 nanofibers. Integrity of this conformal layer was retained even after the calcination of organic fibers (see figure 2(b)). A similar approach was also applied for the fabrication of AlN nanotubes (see figures 2(c) and (d)).
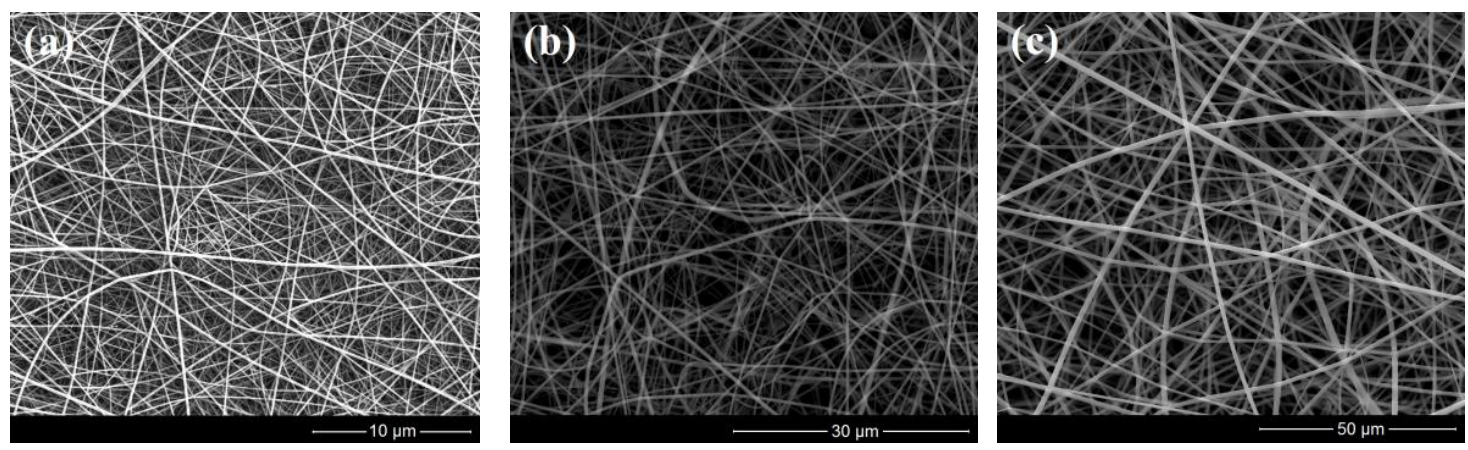

Figure 1. SEM images of electrospun PA66 nanofibers templates having (a) 70, (b) 330, and (c) $\sim 740 \mathrm{~nm}$ average fiber diameter.
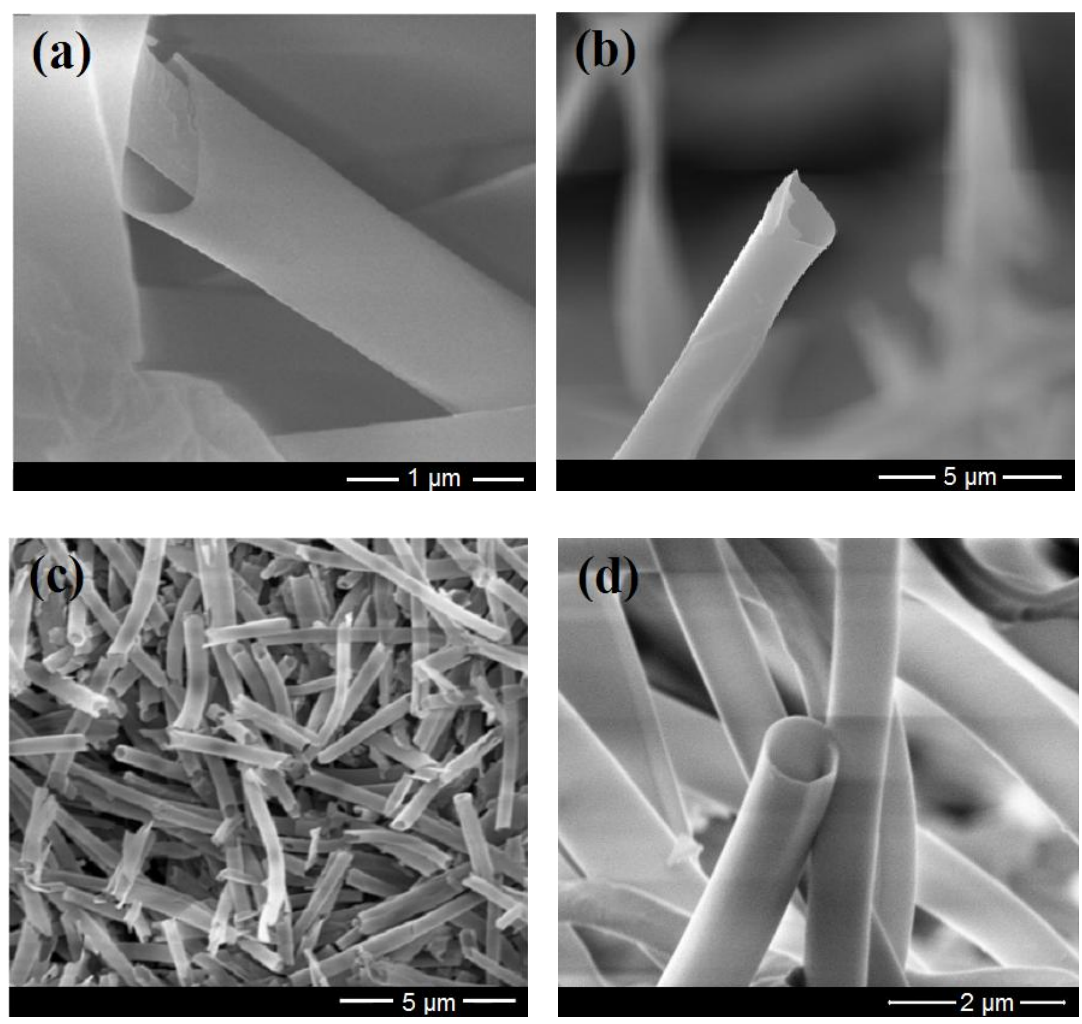

Figure 2. SEM images of $\mathrm{Al}_{2} \mathrm{O}_{3}$-coated PA66 nanofibers before (a), and after (b) ex-situ calcination. SEM images of AIN nanotubes after in-situ calcination $(c, d)$. 
Chemical composition and bonding states of the AlN nanotubes were investigated by using X-ray photoelectron spectroscopy (XPS). Survey scans detected peaks of Al, N, O, and C (see table II). Carbon and oxygen contents of nanotubes were high, indicating the presence of residual organic components. Formation of AlN was confirmed by Al $2 p$ and $\mathrm{N} 1 \mathrm{~s}$ high resolution XPS scans, which are given in figure 3 . Al $2 p$ scan was fitted by two subpeaks located at 73.38 and $74.37 \mathrm{eV}$, corresponding to Al-N [10,11] and Al-O [12] bonds, respectively. $\mathrm{N}$ 1s high resolution scan was also fitted by two subpeaks. The peak located at $396.62 \mathrm{eV}$ was attributed to the N-Al bond [12,13]; whereas the one located at $399.11 \mathrm{eV}$ was assigned as the $\mathrm{N}-\mathrm{O}$ bond [13].

Table II. XPS survey scan results.

\begin{tabular}{|l|l|l|l|}
\hline PA66 Fiber $\boldsymbol{~}$ & $\sim \mathbf{7 0} \mathbf{~ n m}$ & $\mathbf{\sim 3 3 0} \mathbf{~ n m}$ & $\sim \mathbf{7 4 0} \mathbf{~ n m}$ \\
\hline Al (at.\%) & 17.06 & 21.87 & 22.98 \\
\hline N (at.\%) & 9.19 & 7.51 & 13.15 \\
\hline O (at.\%) & 27.16 & 37.14 & 29.51 \\
\hline C (at.\%) & 46.59 & 33.49 & 34.36 \\
\hline
\end{tabular}
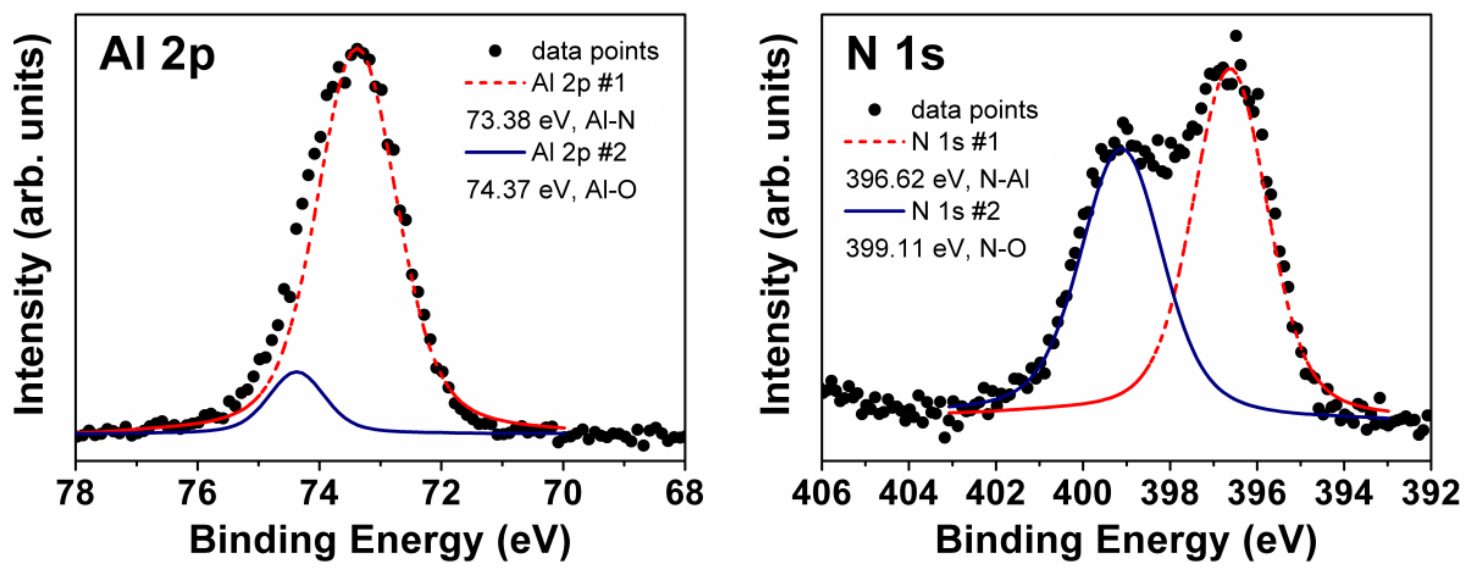

Figure 3. (a) $\mathrm{Al} 2 \mathrm{p}$, and (b) $\mathrm{N} 1 \mathrm{~s}$ high resolution XPS scans of AlN nanotubes fabricated by using $740 \mathrm{~nm}$ diameter PA66 nanofibers.

TEM images of AlN nanotubes fabricated by depositing 800 cycles AlN on PA66 nanofiber templates are given in figures 4(a-d). For all the samples, wall thicknesses were found to be highly uniform. This indicates that precise wall thickness control is possible simply by adjusting the number of ALD cycles. Crystal structure of the AlN film deposited on polymeric templates was studied by high resolution TEM (HR-TEM) and electron diffraction. HR-TEM image of an AlN nanotube fabricated by using $~ 330 \mathrm{~nm}$ diameter PA66 nanofibers is given in figure 4(e). AlN was found to be polycrystalline with nanometer sized grains. This was further confirmed by selected area electron diffraction (SAED). SAED pattern of the same sample (see figure 4(f)) revealed several polycrystalline diffraction rings. 

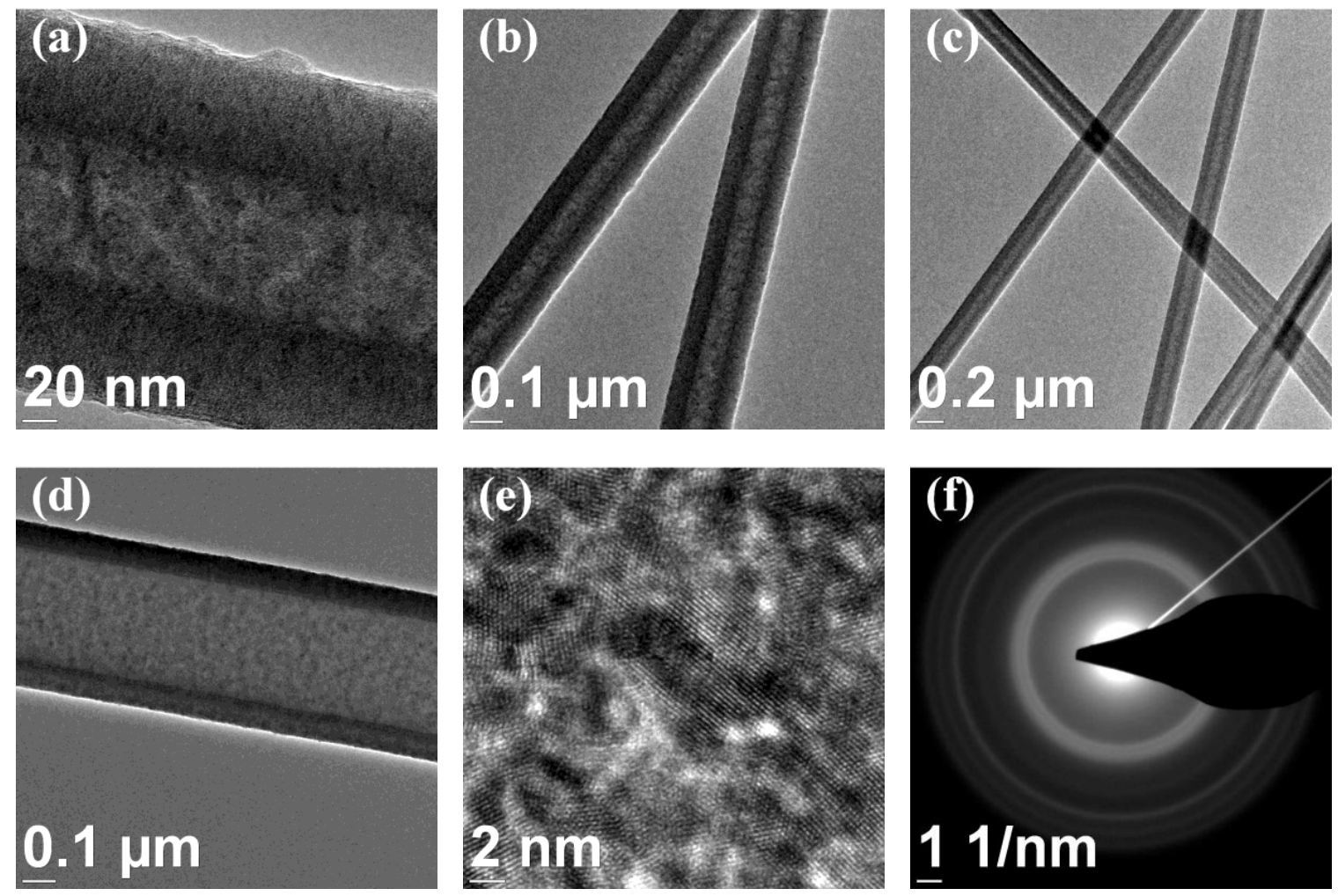

Figure 4. TEM images of AlN nanotubes fabricated by using 70 (a-c), and $~ 330 \mathrm{~nm}$ (d) diameter PA66 nanofibers. HR-TEM image (e) and SAED pattern (f) of AlN nanotubes fabricated by using $\sim 330 \mathrm{~nm}$ diameter PA66 nanofibers.

\section{CONCLUSIONS}

$\mathrm{Al}_{2} \mathrm{O}_{3}$ and $\mathrm{AlN}$ nanotubes were fabricated by depositing conformal thin films on electrospun PA66 nanofiber templates. Depositions were carried out at $200^{\circ} \mathrm{C}$, using thermal and plasmaenhanced ALD processes with deposition rates of $\sim 1.05$ and $0.86 \AA$ cycle for $\mathrm{Al}_{2} \mathrm{O}_{3}$ and $\mathrm{AlN}$, respectively. After the depositions, coated nanofibers were calcinated at $500^{\circ} \mathrm{C}$ for $2 \mathrm{~h}$ in order to remove organic components. XPS survey scans detected high contents of carbon and oxygen in the AlN nanotubes, which was attributed to the presence of residual organic components.

Formation of AlN was confirmed by high resolution XPS peaks located at 74.37 (Al 2p) and $396.62 \mathrm{eV}(\mathrm{N} 1 \mathrm{~s})$. TEM images of the samples indicated uniform wall thicknesses. AlN films deposited on polymeric fibers were polycrystalline as determined by high resolution TEM (HRTEM) and selected area electron diffraction (SAED). 


\section{ACKNOWLEDGMENTS}

This work was performed at UNAM supported by the State Planning Organization (DPT) of Turkey through the National Nanotechnology Research Center Project. N.B. acknowledges support from Marie Curie International Re-integration Grant (Grant \# PIRG05-GA-2009249196).

\section{REFERENCES}

1. M. Ritala and M. Leskelä, in Handbook of Thin Film Materials Vol. 1, edited by H. S. Nalwa (Academic Press, San Diego, 2002) p.103.

2. Q. Peng, X.-Y. Sun, J.C. Spagnola, G.K. Hyde, R.J. Spontak and G.N. Parsons, Nano Lett. 7 (3), 719 (2007).

3. Q. Peng, X.-Y. Sun, J.C. Spagnola, C. Saquing, S.A. Khan, R.J. Spontak and G.N. Parsons, ACS Nano 3 (3) 546 (2009).

4. C.J. Oldham, B. Gong, J.C. Spagnola, J.S. Jur, K.J. Senecal, T.A. Godfrey and G.N. Parsons, J. Electrochem. Soc. 158 (9), D549 (2011).

5. G.-M. Kim, S.-M. Lee, G.H. Michler, H. Roggendorf, U. Gösele and M. Knez, Chem. Mater. 20, 3085 (2008).

6. E. Santala, M. Kemell, M. Leskelä and M.Ritala, Nanotechnology 20, 035602 (2009).

7. J.Y. Park, S.-W. Choi, J.-W. Lee, C. Lee and S.S. Kim, J. Am. Ceram. Soc. 92 (11), 2551 (2009).

8. S.-W. Choi, J.Y. Park and S.S. Kim, Nanotechnology 20, 465603 (2009).

9. J.Y. Park, S.-W. Choi and S.S. Kim, Nanotechnology 21, 475601 (2010).

10. N. Duez, B. Mutel, O. Dessaux, P. Goudmand and J. Grimblot, Surf. Coat. Tech. 125, 79 (2000).

11. D. Manova, V. Dimitrova, W. Fukarek and D. Karpuzov, Surf. Coat. Tech. 106, 205 (1998).

12. L. Rosenberger, R. Baird, E. McCullen, G. Auner and G. Shreve, Surf. Interface Anal. 40, 1254 (2008).

13. H.M. Liao, R.N.S. Sodhi and T.W. Coyle, J. Vac. Sci. Technol. A 11(5), 2681 (1993). 